temperature of about $43^{\circ} .5$ over the whole area, and confirm all the provisional conclusions stated above. The figures observed in the three typical positions are as follow :-

$$
\begin{array}{lll}
\text { Place } & \ldots & \text { Channel. } \\
\text { Date } & \ldots & \text { March } 30 .
\end{array}
$$$$
\text { Off Skate Island. }
$$

Strach:Ir.

Temp. surface

$$
\text { ... } 44^{\circ} 7
$$

Marcil 29.

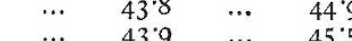

From the forms of the curves the spring minimum appears to be past, and over all the temperature is about $2^{\circ} \cdot 5$ higher than at the same period last year. The water in Upper Loch Fyne is now cooling at the bottom and heating again on the surface, the range for the year at great depths having been only $4^{\circ}$. The actual change of temperature in the sea-area between the beginning; of February and the end of March is very slight, but it is significant in showing by its direction that the period of minimum lay between the two.

One interesting application of the observations may be made to climatology. A great proportion of the heat gained is derived not from solar radiation, or the contact of heated air with the surface, but from the warm Atlantic water entering by the tides. Since the water on the Plateau appears to remain warmer than that inside all the year round, no heat is lost to the Atlantic in winter; but all must be radiated off from the surface or employed in evaporating water or heating air by contact, and in this way more heat is returned to the air of the Clyde sea-area in winter than was received from it in summer. Another observation may be meationed which serves to show how important a bearing temperature observations may have on biology. On February 4, four tow-nets were used off Strachur at different depths: one at 70 fathoms, one at 50 , one at 30 fathoms deep, and the fourth at the surface. There was nothing in the surface-net, and the surface temperature was $43^{\circ}$. The contents of the other three nets were examined by Mr. David Robertson, of Millport, who reports :- "In all three nets Copepoda were moderately abundant. The nets at 70 and 30 fathoms contained one and the same species; but the contents of the net at the middle depth were different, confined to an abundant species of copepod loaded with ova (Euchata norvegica). With them there were two or three adult schizopods (Nyctiphanes norvegica)." At 70 fathoms the temperature was $45^{\circ} .9$, at 30 fathoms $45^{\circ} 6$, and at the position of the middle net $46^{\circ} 3$. Mr. Robertson concludes: "As the middle water of the loch at this time is shown to be warmer than either the layer above or below, we may reasonably assume that the species in ova sought the warmer layer." Similar observations repeated at many different places during the March trip showed the same result, the minute Crustacea being most abundant where the temperature was highest.

The work is being carried on meanwhile, purely as a piece of physical and meteorological research, and a considerable time must necessarily elapse before all the latent meaning of the great mass of figures now being accumulated can be brought to light. There is no doubt that when the problem of the interchanges of heat in comparatively deep water has been made out, important practical applications to other sciences, and to some arts and industries, will be discovered.

HUGH ROBERT MILL.

\section{SCIENCE AND GUNNERY'1}

II.

I AST week we pointed out the great advantages which accrue from retiring guns behind inconspicuous parapets, and mentioned that the energy of the discharge had been utilised to raise the guns again into the firing position without the aid of extraneous power.

$$
\text { × Continued from p. } 37 \text {. }
$$

The theory of the discharge of cannon involves many interesting considerations, not only with respect to the strength and structure of the guns but also with reference to the force required to control the recoil. A gun may be considered as a heat engine of the simplest construction, performing its work in one stroke. The fuel used is gunpowder, and the energy developed is, as in other engines of this class, in proportion to the weight of fuel used and to the heat it is capable of developing. The main difference between explosives and most other fuels is that explosives are complete in themselves; that is to say, they burn independently of the presence of extraneous bodies, and that consequently the chemical union which causes the explosion takes place simultaneously throughout the mass and in an exceedingly short time.

Fuel in large masses burns slowly because the air, which forms its complement, can come into contact with only limited surfaces, but if reduced to fine powder the combustion may be made to assume almost the intensity of an explosion, as for example in the dust-fuel used in Crampton's furnace, and the dusty atmosphere of coalmines and flour-mills.

The materials in gunpowder, intimately mixed through. out, are in a state of unstable equilibrium with respect to each other; a very moderate increase to the thermal movement of the molecules causes them to clash together with sufficient energy to insure combination, and if such increase of motion be communicated to one portion of the explosive by the application of percussion or of a hot body, it is carried through the mass by the luminiferous ether with all the rapidity with which radiant energy travels, and the increase of motion, sufficient to cause combination, is communicated to every molecule nearly simultaneously, the consequence being a change of form and volume produced with the suddenness which marks an explosion. We believe that Mr. Anderson was the first, in his lectures on heat at the Society of Arts, to point out that it is unfair to compare the calorific value of fuels in their incomplete form ; that is to say, that such fuels as require air for combustion should have the necessary weight of air added to them, and when that was done the singular fact appeared that the quantity of heat evolved by most combustibles per unit of weight was very nearly the same; thus in nine cases cited, which included coal, coke, wood, petroleum, illuminating gas, and gunpowder, the extreme variations from the mean calorific value did not exceed 9 per cent. In the same lectures it was shown that in guns, as in most heat-engines, a very large proportion of the thermal energy of the fuel was dissipated in a useless manner; in the case of cannon more than half was wasted in heating up the gun, and about one-third only in producing recoil, which was the reaction to the energy communicated to the shot, to that imparted to the powder gases, and to the work of displacing the atmosphere Of these three effects only the energy imparted to the shot was known with precision, for by means of sufficiently simple apparatus it was possible to determine with great accuracy the velocity with which the projectile left the gun, and the energy therefore was easily determined by multiplying half its mass by the square of that velocity.

The determination of the work done in expelling the powder gases was more difficult to estimate. In the first place, only about 43 per cent. of the products of the combus. tion of gunpowder are in the state of gas, the remaining 57 per cent. are in the form of very finely-divided solids ; next, the combustion goes on nearly all the time that the shot is travelling out of the gun, the pebbles of powder igniting in succession, a fact which is proved by the circumstance that in short guns a good deal of powder is blown out without being consumed at all, and it is doubtful even whether in the modern long guns combustion is always complete. While the shot is travelling along the chase, the centre of gravity of the powder charge is moving also 
at an uncertain rate, but the moment the shot leaves the gun the whole of the products of combustion appear to spring out with a velocity equal to, if not greater than, that of the shot. The evidence of this supposition is found in the fact that in the case of disappearing guns fired with their muzzles close to a masonry parapet, and in which the recoil below it is completed in a small fraction of a second, no blackening of the masonry is noticeable. A portion of the gases follow the shot and keep up with it for a considerable distance, as is shown by the circumstance that smoke issues plentifully from the earth banks into which proof shots at short range are fired, proving that the smoke of the discharge must have followed the shot into the tunnel momentarily made and as quickly obliterated by passage of the projectile through the earth. It is evident that the velocity with which the gases issue must depend upon the pressure in the gun at the moment of the shot leaving the muzzle, and this pressure again depends upon the volume of the bore, the weight of powder consumed, and the final temperature, the latter depending partly upon the expansion and the consequent heat converted into work.

The final temperature of the gases can only be conjectured : it probably does not exceed a bright red heat, or between $1200^{\circ} \mathrm{C}$. and $1400^{\circ} \mathrm{C}$. absolute; and knowing that one pound of powder at $0^{\circ} \mathrm{C}$. and standard barometer develops about 448 cubic feet of gas, it is possible to estimate what the final pressure in the gun should be. Given, however, a barrel full of gas at a definite pressure, we are not in a condition to say what energy its expulsion would generate; and the assumption that the mean velocity will be that due to a body falling from a height equal to that of a column of gas of uniform maximum density which would correspond to the observed pressure would probably be as accurate as any other. On that assumption the velocity of the gas would be 4544 times the square root of the product of the final pressure in the bore in tons per square inch into its volume in cubic feet divided by the weight of the powder in pounds, and, this velocity determined, the energy is, of course, at once arrived at.

The displacement of the atmosphere also forms a very considerable item. The expansion on leaving the gun being instantaneous, the pressures and temperatures fall approximately as in adiabatic expansion; hence it is easy to calculate what probable temperature and consequent volume the gases will assume as they stream out of the gun, and this temperature is comparatively low; otherwise powder smoke would be insupportable to those feeling its influence close to a gun. The work done in displacing the air is found by multiplying the volume pushed aside by the atmospheric pressure. A small portion of this work is performed as the shot travels along the chase, but the greater part is done after it leaves the muzzle. The energy of the reaction to the sudden liberation of gases under high pressure is but too familiar to us in the case of boiler explosions, in which it commonly happens that great masses of material are hurled with destructive force and often to great distances.

The pressure-curve inside the gun is still very illdefined; the forms commonly given are certainly a long way from the truth, because the areas included, which form indicator diagrams representing the work done, will not account for the energy developed. The pressure probably falls in proportion to the distance travelled by the shot, and the time in which the discharge takes place may be calculated on that assumption, or even with sufficient accuracy on the supposition that the velocity of the shot is uniformly accelerated as from the action of a constant force equal to the mean pressure producing the known velocity of the shot in a known distance. The easiest way to take account of all the forces causing recoil is to ascertain the velocity of the combined powder and projectile which will possess the total energy of discharge calculated, and then to equate the momentum of the gun and moving parts of the carriage to that of the shot and powder. In the case of a carriage receding along a slide, this operation is a very easy one, but when a Moncrieff mounting has to be dealt with, the case becomes very complicated, the gun moves along a curved path, the sides and counterweights have a rolling motion, and it becomes necessary to calculate the path of the centre of gyration, and determine the virtual weight concentrated in the gun, and a similar process has to be followed in the case of the massive levers which carry the guns in hydro-pneumatic mountings.

Recoil consists of two parts : first, the period, a very brief one, in which the velocity of recoil is got up ; and secondly, the period in which the energy so acquired by the parts in motion is more slowly absorbed or dissipated. The first part of recoil must necessarily occupy the same time as the discharge, that is to say, a small fraction of a second, because acceleration can only go on so long as the accelerating force is acting, but that force is the pressure of the powder gases on the base of the bore, and the pressure only lasts while the discharge is taking place. The motion of the whole system of gun and carriage does not, however, coincide with the motion of the shot. In all but very long guns the shot has left the barrel before the motion of the muzzle commences ; during the time of discharge, perhaps the $1 / 50$ part of a second, the gun is being stretched by the inertia of its forward end and of the carriage resisting the tendency to put them into motion, but the reaction to this stretching carries on the acceleration of recoil a little after the shot has left the gun. The pressure on the parts during this period is very severe, the work done being exactly the same as that performed by the shot, the powder, and the displacement of the atmosphere. The full speed of recoil is attained, not only in a very short time, but in a very restricted space, rarely more than 3 inches, and the difficulty in constructing carriages may be said to lie in providing for the violent strains which produce a velocity of some 20 feet a second in the great mass of the gun and carriage in the exceeding short time and space named. The momentum of the moving parts of the system being equal to that of the ejected charge, the velocity is readily calculated, and generally ranges between 16 and 30 feet per second, and their energy is then easily ascertained.

In the counterweight Moncrieff carriages, which have been made for short muzzle-loaders up to 9 -inch calibre and twelve tons weight, the whole mass set in motion is so great compared with the energy of the discharge, that the gun sinks below the parapet with a comparatively slow and stately movement; but, with the long breechloaders and heavy charges, with the comparatively light moving parts which characterise hydro-pneumatic mountings, the motion is very violent, and requires great strength in the parts to resist the strains. In addition, the gun describes a circular path, and by the time the maximum velocity of recoil is attained, sufficient centrifugal force is engendered to produce a sudden upward pull, which has to be met by arrangements for holding the carriage down to the masonry of the emplacements. The longer the arms which carry the gun, the less this tendency is, because the pull of centrifugal force is inversely as the length of the radius of the curve described by the trunnions. The front of the carriage has generally to be held down for another reason. The gun, when fired, is high above the base of the mounting; the mechanism, self-contained in the carriage, for absorbing recoil, offers a certain amount of resistance to the backward movement of the gun, hence a couple is established which tends to turn the carriage over on its rear wheels, and this tendency varies with the height of the gun and the length of the base. 
In the hydro-pneumatic system the fall of the gun actuates a ram or piston working in a cylinder full of water, and communicating by an automatic valve, opening outwards from the cylinder, with an air-vessel about two and a half times the capacity of the ram, and filled with air compressed to a degree sufficient not only to support the weight of the gun, but also to raise it quickly into the firing position. When the gun is up, the air-vessel is nearly empty; when down, a volume of water equal to that of the ram displaces the air and increases its pressure, and the ratio of the fall of the gun to the stroke of the ram, and the relative velocities of the two, are so adusted that the increase of air-pressure corresponds to the increasing leverage which the gun acquires as it descends.

It is possible to provide sufficient air-pressure not only to arrest the fall of the gun, but also to absorb the energy of recoil ; but unless the gun is allowed to fall a very great distance this is not necessary, and any excess energy can be more conveniently absorbed by regulating the opening of the recoil-valve so as to throttle the water in its passage from the cylinder into the air-vessel. At first sight it might be assumed that, saving friction of the mechanism, the air-pressure which would suffice to check the fall of the gun would be sufficient to raise it again ; but a little consideration will show that this is not the case. To allow the gun to fall in the short space of time during which recoil takes place, the pressure of the air must be less than that necessary to support the gun, because its pressure rises nearly according to the ordinates of an adiabatic curve, the temperature rising in exact proportion to the work done. During the time the gun is being loaded, the heat developed in the air is dissipated, so that when the gun requires to be raised the store of heat is gone, and the air, expanding, falls in temperature by the amount of heat converted into the work of raising the gun ; the pressure consequently falls.

To meet these two sources of loss, amounting to the heat corresponding to the work of the gun falling twice the height to which it rises and falls, the energy of the discharge has to be drawn upon; it compresses the air far above its isothermal line, although that line is so fixed as to yield sufficient heat for conversion into the work of raising the gun. In addition, the energy of discharge has to provide the means of ovarcoming the friction of the machinery which resists the falling of the gun, and again resists its rising, so that, taking all the sources of loss enumerated together, the energy of recoil of even our most powerful guns is not adequate to do more than allow them to fall some 8 or 9 feet, an amount, however, sufficient for the most ample protection.

It will be readily seen that the construction of a disappearing carriage offers a number of problems of great scientific as well as practical interest. We have only dwelt upon some of the most prominent points. There remain the strains on the elevating gear, which is arranged so as to bring the gun into the same loading position, irrespective of the angle at which it is fired, and has, therefore, to communicate a sudden rotatory motion to the gun; the resistance of the levers and elevating. bars to the cross strains caused by their own inertia when brought into sudden motion sideways; the resistance offered to the water in its passage at variable velocities from the cylinder to the air-vessel, the accelerating force to be provided to raise the gun in a given time, and many minor problems which tax to the full the application of mathematics to the design of machinery.

\section{THE TOTAL SOLAR ECLIPSE OF AUGUST 19, I887.}

THE total eclipse of the sun which will occur on August 19 next, though only of average duration, will offer exceptional opportunities for observation from the circumstance that the track of the moon's shadow will be almost entirely a continental one, in striking contrast to the eclipses of the last four years, in all of which the shadow has followed a course which has been principally over the great oceans. The eclipse is technically a partial one for the principal part of Great Britain, but as it will be nearly over before sunrise, it will practically not be visible here. The middle phase will have been reached at sunrise, for places a little to the west of Berlin : and this city lying within the path of the shadow, it is just possible that it may be favoured with a sight of the phenomena of totality, though with a sun close to the horizon; for the sun will be largely obscured as it rises, and will not be quite $3^{\circ}$ high at the end of the total phase. From Prussia the shadow track passes into Russia, and the central line does not leave the borders of the Russian Empire until it reaches East longitude $112^{\circ}$. It then crosses Manchuria and the Sea of Japan, and cuts the principal island of the Japanese group a little to the north of the capital. The final portion of its course lies over the North Pacific Ocean, and except for the little island of Rico de Oro, it does not touch land again. But the path of totality not only lies mainly over land, a large number of important towns are either actually included within, or lie very close to its limits. Königsberg lies just outside. Kovno, Wilna, and Vitebsk, are well within the shadow; Wilna being nearly on the central line. At these towns, however, the sun will still be too low for them to afford desirable stations for observations, and probably the neighbourhood of Moscow will be the nearest district which will be occupied by astronomers. At Moscow itself, the eclipse will not be quite total, since that city lies just outside the southern edge of the shadow-track, but three lines of railway radiating from Moscow will afford easy access to places actually on the central line. The most westerly of these three railways is that which unites St. Petersburg with the older capital, and which passes through Twer. Twer is nearly on the central line, but a little to the north of it. The sun will have an elevation of about $16^{\circ}$ in this neighbourhood, and the maximum duration of totality is not quite two minutes and a half. At Twer itself it will be only I 24 seconds. Three parties, two German, and one French, will take up positions within the Government of which Twer is the capital. The second line runs from Moscow to Vologda, passing through Jaroslavl, which lies within but near the edge of the shadow. Petrowsk on this railway is very near the central line, and here the sun will be $2^{\circ}$ higher than near Twer, and the duration 152 seconds. The third line runs to Kineshma, which is itself very near the central line. Here the sun will be about $20^{\circ}$ high, and the total eclipse on the central line will last 156 seconds. It will not, however, be difficult to proceed to yet more favourable positions further east. From Moscow there is a line through Nijni Novgorod to Kazan, and a service of river steamers runs thence up the River Kama to Perm. Perm lies to the south of the central line, but the totality lasts there 173 seconds, whilst the sun is $28^{\circ}$ high at mid eclipse. If the weather should be favourable, Perm would be therefore a very suitable station for those astronomers who can spare the time to journey so far; for others the neighbourhoods of Petrowsk and Kineshma will afford readily accessible sites. Prof. Bredichin, Director of the Moscow Observatory, has his own private observatory only two kilometres from Kineshma, and very close to the central line ; and he has generously offered the hospitality of his house to the Royal Astronomical Society for two English astronomers, an offer which has been gratefully accepted by the Society, on behalf of Dr. Copeland and the Rev. S. J. Perry. Prof. C. A. Young also will have his station here, and a strong party of Italian and English astronomers, consisting of Profs. Tacchini and Kiccò, and Messrs. Common and Turner, will be located at no great distance away, in the neighbouring Government of Vladimir. 